Thorax (1967), 22, 567.

\title{
Safe per-operative anticoagulation
}

\author{
J . W I E B E R D I N K
}

From the Department of Cardiovascular Surgery, University Hospital, Utrecht, Netherlands

\begin{abstract}
Pre-, per-, and post-operative anticoagulation at the therapeutic level is nowadays the most, if not the only, available effective method to prevent post-operative thrombo-embolism. There is no increased tendency to bleeding to be feared during the operation. The real danger of this prophylaxis consists of a treacherous tendency to acute relative overdosage after the operation. This is explained by the combined indirect action of anticoagulants and influences related to the operation. As its development can accurately be followed by laboratory tests, dangerous levels of anticoagulation can be prevented. Experiences in 242 surgical patients are presented to demonstrate the efficacy of the following post-operative routine: Coagulation studies (prothrombin time or thrombotest) at least twice daily during one week; fractionated administration of anticoagulants and, if necessary, small amounts $\left(0 \cdot 25-1 \mathrm{mg}\right.$.) of vitamin $\mathrm{K}_{1}$. The results suggest that with this policy the risk of thrombo-embolism in surgery can be considerably reduced, if not abolished.
\end{abstract}

Anticoagulation at the time of surgery is desirable for several reasons.

First, treatment of thrombosis, even if it is started at the first or even doubtful manifestation of the post-operative complication, does not significantly reduce the frequency of lethal pulmonary embolism. The mortality of thrombosis still amounts to one in every few hundred operations and continues to cast a shadow over modern surgery, including minor operations in young adults. Embolectomy, even with the stand-by of extracorporeal circulation, does not save more than a fraction of the many who die annually from post-operative pulmonary embolism (Cooley, Beall, and Alexander, 1961 ; Cross and Mowlem, 1963 ; Editorial-Circulation, 1966 ; Foley and Wright, 1956 ; Wieberdink, 1960).

Prevention of sudden death from post-operative thrombo-embolism is attained only by prophylactic anticoagulation starting before the operation. This is explained by the probability that intravenous clotting may start during the operation, and by the fact that non-obstructive thrombi must be considered the most dangerous (Borgström, Greitz, van der Linden, Molin, and Rudics, 1965; Littman and Brodman, 1955; Matis, 1961 ; Müllertz and Storm, 1954 ; Sevitt and Gallagher, 1961 ; Storm and Gammelgaard, 1957 ; Storm, 1958).

Secondly, prophylactic anticoagulation is desirable because the long-term sequelae of thrombosis (venous insufficiency in the lower extremities) are not completely prevented by early treatment with anticoagulants (Borgström et al., 1965 ; Editorial -Circulation, 1966; Foley and Wright, 1956).

Thirdly, thrombo-embolism is one of the major problems of intracardiac surgery. This knowledge dates back to the earliest experiences with blind mitral commissurotomy, especially if performed in the presence of auricular fibrillation. In modern times valve replacement has revived this problem as thrombo-embolism constitutes the main longterm hazard of prosthetic valves.

Fourthly, anticoagulation seems to improve, to a limited extent, the results of disobliterative arterial surgery. Most vascular surgeons consider some prevention of clotting (with heparin or coumarin) during at least some phase of the operation to be a logical and valuable part of their routine.

From the pharmacological point of view, coumarin derivatives or antivitamins $K$ (also called anticoagulants, in contrast to heparin) are probably the best drugs for per-operative use because they are thought to impede at the therapeutic level intravascular clotting without seriously disturbing the mechanisms of haemostasis-for instance, platelet-function (Alexander, 1961; Baugh, 1965 ; Foley and Wright, 1956; Jaques, 1962 ; Lüscher, 1959 ; O'Reilly, Aggeler, and Leong, 1963 ; Tocantins, 1947). This could mean that less risk of thrombosis exists without abnormal danger of bleeding. In this respect anticoagulants are superior to heparin; the additional 
risks of heparin, well known from extracorporeal circulation, are not considered here.

Surgeons, and laboratory experts in the field of clotting, have formed divergent views on the risk of per-operative anticoagulation with coumarin derivatives. Though some surgical reports have stressed the absence of any increased tendency to bleeding during the operation (Borgström et al., 1965 ; Cleland, 1964 ; Littman and Brodman, 1955; Matis, 1961 ; Müllertz and Storm, 1954 ; Sevitt and Gallagher, 1961 ; Storm and Hansen, 1955; Storm and Gammelgaard, 1957 ; Storm, 1958), most surgeons reject the prophylactic use of these drugs because this might cause a haemorrhagic 'diathesis' during the operation.

The author came to doubt this surgical opinion some years ago when it was found that major arterial surgery could be accomplished during anticoagulation at the therapeutic level without any increased tendency to bleeding. It was noticed that post-operative bleeding occurred rather often. These haemorrhages were always found to be linked with pathological tests-prothrombin-time (P.T.T.) or thrombotest (T.T.)-and seemed, therefore, to be characterized by acute overdosage. The explanation of this phenomenon was probably the combined, indirect action of coumarin derivatives and influences related to the operation. These included anaesthetic drugs, stress, sedatives, and antibiotics, as it was well known at that time that the main reasons for disturbances in longterm anticoagulation are intercurrent diseases and the simultaneous use of drugs such as salicylates, barbiturates, and antibiotics (Jordan, 1962).

An investigation was undertaken which confirmed the hypothesis (Kluft, Stortenbeek, de Vries, and Wieberdink, 1965). In other words, it established some agreement between the observations of surgeons and the pharmacology of anticoagulants. This was considered a sound basis for another investigation, which is reported here. Its working hypothesis may be summarized as follows :

Anticoagulation at the therapeutic level is effective in preventing thrombosis without increasing the risk of bleeding during the operation. Following operative intervention (after an interval appropriate to the indirect actions of these drugs) toxic levels of anticoagulation tend to be reached by the combined effect of anticoagulants and influences related to the operation. As this relative overdosage is reflected in the results of laboratory tests, its prevention should be possible by close control of the level of anticoagulation (measured by P.T.T. or T.T.) and by fractionated administration of coumarin derivatives and of vitamin $\mathbf{K}_{1}$.

Other risks of anticoagulation are not considered in this study. It is self-evident that safe prophylactic anticoagulation in surgery demands the exclusion of established contraindications, such as peptic ulcer and cerebral haemorrhage.

\section{MATERIAL AND METHODS}

Since 1961 the author has used prophylactic anticoagulation in a variety of adult patients, starting with the prescription about one week before the operation and aiming at a P.T.T. of 10 to $15 \%$ (or two to two and a half times the control value) or a T.T. of 8 to $12 \%$. No other prophylaxis of thrombosis (such as bandaging of the lower limbs) was practised; on the contrary, as confidence in anticoagulation grew, early ambulation was not advised if it could be harmful from other points of view (for instance, in arterial disobliterations crossing over a joint).

The circumstances in which the investigation had to be undertaken did not allow uniformity of the collected data. Most of the patients reported here were operated upon in the Department of Cardiovascular Surgery of the University Hospital, Utrecht (cardiovascular patients), and in the Military Hospital Dr. A. Mathijsen, Utrecht (vascular patients). A number of others (cardiovascular operations, sympathectomies, and pulmonary resections) treated in several private hospitals are included. An advantage of this is that it has been possible to examine the feasibility of this prophylaxis of thrombo-embolism under different conditions. In the analysis of the material it proved practical to distinguish between 'P.T.T.-cases' and 'T.T.-cases,' according to the laboratory technique used (Table I).

Earlier experiences had shown that the changes in the post-operative level of anticoagulation may be treacherous. In the critical period, one to two days after the operation, this level may change within a few hours from safely therapeutic to severely toxic. This made caution and alertness essential. From these pilot experiences the following policy was adopted:

During the week preceding the operation the P.T.T. or T.T. was determined daily. From the day of the operation until at least one week later, these tests were performed at least twice a day, usually early in the morning and late in the afternoon. Often (during the day and night) additional tests were considered necessary in order to follow the trend in the level of anticoagulation and to prescribe corrective doses of coumarin or vitamin $\mathbf{K}_{1}$.

The anticoagulants used were mainly nicoumalone (Sintrom) and warfarin. If post-operative disturbances of absorption could influence oral use, intravenous administration was always preferred (Kluft, Wieberdink, and de Vries, 1963). 
T A B L E I

PATIENTS (ADULTS) ACCORDING TO LABORATORY METHOD USED AND TYPE OF OPERATION GROUP

\begin{tabular}{|c|c|c|}
\hline \multirow{2}{*}{ Operation Group } & \multicolumn{2}{|c|}{$\begin{array}{l}\text { Laboratory } \\
\text { Method Used }\end{array}$} \\
\hline & P.T.T. & T.T. \\
\hline $\begin{array}{l}\text { Cardiac (including transthoracic pacemaker } \\
\text { implantations and open-heart surgery with } \\
\text { the aid of extracorporeal circulation) } \\
\text { Arterial (including resections of aortic } \\
\text { aneurysms; mainly arterial disobliterations) } \\
\begin{array}{l}\text { Venous (mainly varicose veins) } \\
\text { Lumbar sympathectomies }\end{array} \begin{array}{l}\text { Miscellaneous (mainly lung resections, ex- } \\
\text { ploratory thoracotomies, and amputations) }\end{array}\end{array}$ & $\begin{array}{r}1 \\
45 \\
16 \\
17 \\
23\end{array}$ & $\begin{array}{r}54 \\
39 \\
33 \\
7 \\
7\end{array}$ \\
\hline Total & 102 & 140 \\
\hline
\end{tabular}

As a rule, on the morning of the operation a smaller dose was prescribed than on the preceding days. Guided by the P.T.T. or T.T., subnormal doses proved effective in most cases during at least five post-operative days. Often it took one to two weeks before the patient returned to his pre-operative daily doses.

If the P.T.T. or T.T. approached toxic values, vitamin $K_{1}$ was usually not prescribed immediately. Every one or two hours the tests were repeated until restoration to the therapeutic level proved safe. If no improvement occurred in a few hours, vitamin $\mathbf{K}_{1}$ was administered in fractionated doses, checked by P.T.T. or T.T. after one to two hours. Amounts of 5 to $20 \mathrm{mg}$. (which are commonly recommended to treat overdosage) proved to be inadequate, as the therapeutic level of anticoagulation could usually not be regained for days. One or more times 0.25 to $1 \mathrm{mg}$. vitamin $K_{1}$ was found to correct the intoxication without the draw-back of overshooting.

It is evident that the alertness of laboratory technicians, nursing staff, and medical personnel is essential to the safety of this policy, and this prophylaxis of thrombo-embolism puts a heavy burden on the hospital, and especially on its laboratory facilities.

\section{RESULTS}

The Figure gives a representative example of the medication and the level of anticoagulation in our material.

Table II shows the mean level of anticoagulation in the 'P.T.T. and T.T.-cases' before, during,

\section{T A B L E I I}

MEAN PERCENTAGE LEVEL OF PRE-, PER- AND POST OPERATIVE ANTICOAGULATION ACCORDING TO P.T.T OR T.T.

\begin{tabular}{|c|c|c|c|c|c|c|c|c|c|c|c|c|}
\hline & & & & & Day & & & & & & & \\
\hline & & Pre- & ope & rative & $\begin{array}{l}\text { Oper- } \\
\text { ation }\end{array}$ & & & ost- & ope & rativ & & \\
\hline & & 4 & 3 & 2 & 0 & 1 & 2 & 3 & 4 & 5 & 6 & 7 \\
\hline $\begin{array}{l}\text { 'P.T.T. cases' } \\
\text { 'T.T. cases' }\end{array}$ & $\begin{array}{l}70 \\
63\end{array}$ & 38 & 21 & 16 & $\begin{array}{l}12 \\
10\end{array}$ & $\begin{array}{l}16 \\
13\end{array}$ & $\begin{array}{l}15 \\
12\end{array}$ & $\begin{array}{r}11 \\
9\end{array}$ & $\begin{array}{l}12 \\
10\end{array}$ & $\begin{array}{r}13 \\
9\end{array}$ & & $\begin{array}{l}12 \\
11\end{array}$ \\
\hline
\end{tabular}

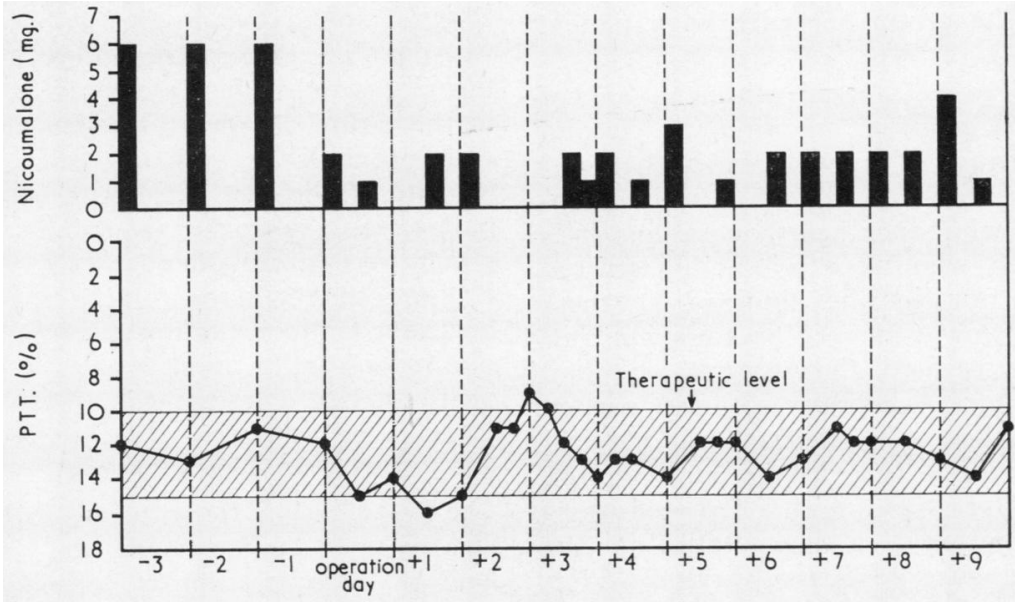

FIGURE. Representative case: a 53-year-old man with arterial disobliteration. Doses of nicoumalone and the level of anticoagulation (P.T.T.) are shown. Pre-operatively the therapeutic level of anticoagulation was satisfactorily maintained with a daily dose of $6 \mathrm{mg}$. nicoumalone. During the first post-operative days considerably lower doses are required to continue this level. A tendency to instability during this period is compensated by fractionated administration, guided by multiple P.T.T. determinations. Vitamin $K_{1}$ was not required. After a week there was a gradual return to pre-operative dosages. 
and after operation. From this Table it is apparent that there has been a tendency to remain 'on the safe side' with the prescription of anticoagulants during the first few days after operation. This is a tendentious attitude, which in fact prefers a certain risk of thrombosis rather than bleeding.

No patient died of pulmonary embolism. Though the numbers are too small to be significant in this respect, some support for this favourable result might be derived from the fact that it included a considerable number of older patients who had atrioventricular block or arterial insufficiency. In no instance did the typical clinical picture of non-lethal pulmonary embolism, or of phlegmasia dolens, develop. Lung complications occurred; but in only three was pulmonary embolism mentioned (for reasons of completeness) in the differential diagnosis of changes that were almost certainly due to infection or atelectasis.

The other favourable result of the investigation concerned the frequency of bleeding during and after the operation. As reported by others and as noticed in earlier personal experiences, no increased tendency to bleeding was observed during the surgical interference. In order to avoid the influence of prejudice one should compare a series of anticoagulated patients with a control group, in which the degree of bleeding during the operation has been judged by an experienced surgeon who does not know the group to which each patient belongs.

Some cardiac cases, treated with the aid of extracorporeal circulation, required a second thoracotomy because of post-operative haemorrhage. Neither in the frequency of these interventions (compared with open-heart operations in a group of children who were not anticoagulated pre-operatively), nor in the findings at these explorations was any evidence for anticoagulantintoxication demonstrated. One patient who had had a blind mitral commissurotomy needed re-operation because of bleeding; a surgical explanation, namely a leak in the atrial suture line, was found. One patient with a femoral artery disobliteration developed a haematoma in the wound. Here, the cause was a non-corrected overdosage: by mistake, vitamin $\mathbf{K}$ was administered instead of vitamin $K_{1}$, leaving a toxic level of anticoagulation untreated for several hours, during which bleeding occurred.

In no case did the laboratory tests give inadequate information concerning the level of anticoagulation. The close follow-up of the level of anticoagulation, measured by P.T.T. or T.T., provided an efficacious safeguard against bleeding. This is similar to acute overdosage in a nonoperated patient. Here, every physician will fear critical changes in the level of anticoagulation, occurring within a few hours, one or two days after administration. It is common practice to deal with such a situation by frequent laboratory tests and the prescription of vitamin $K_{1}$. The same policy has to be followed in the post-operative course of a prophylactically anticoagulated patient, where acute relative overdosage occurs because of the combined effect of a normal (or even subnormal) dose of coumarin and the operation. The opinion of many surgeons, that coumarin may cause a haemorrhagic diathesis in the presence of favourable laboratory tests (Baugh, 1965), was contradicted in this investigation by multiple tests, demonstrating that within a few hours critical changes may occur. We have not encountered a pathological bleeding tendency if, at the same time, the P.T.T. or T.T. were at the therapeutic level. Confidence in these tests has resulted from this study.

During the period of this investigation a seeming paradox was noticed: minor operations (for instance, lumbar sympathectomies) were more liable to be followed by overdosage than were more extensive interventions (cardiac operations and arterial disobliterations). The probable explanation is that blood transfusions counteract the effect of anticoagulants (Kettenborg, de Vries, and van der Pol, 1955 ; Thies, 1961). This is possibly the reason why mitral commissurotomies belong to the group of operations in which good results with prophylactic anticoagulation were achieved, in spite of the fact that the essential risk of this policy (post-operative bleeding) was not suffciently recognized (Stephenson, 1966 ; Storm and Hansen, 1955). In the routine application of peroperative anticoagulation the risk of 'overshoot' should be kept in mind, especially in patients who have not had a transfusion.

\section{DISCUSSION}

The investigation seems to me to have restored a link between surgeons and the specialists in the field of blood-clotting. Operations can be performed safely at the therapeutic level of anticoagulation. There is a considerable risk of bleeding, characterized by (relative) overdosage, starting one to two days after the operation and sometimes reaching dangerous levels within a few hours. These bleedings can be misinterpreted as being caused by a haemorrhagic diathesis during the operation, if prejudices against prophylactic anti- 
coagulation exist and if laboratory tests are not performed with sufficient frequency to clarify the danger. From this point of view, the most important risk of prophylactic anticoagulation is that acute intoxication tends to occur after it is expected. On the other hand, this danger is avoidable if the underlying mechanism is recognized. By this conception thrombo-embolism, a sword of Damocles as old as surgery and still hanging over many patients, can be removed. This result can only be attained by the alertness of all concerned with the post-operative care and laboratory work.

\section{REFERENCES}

Alexander, B. (1961). A guide to anticoagulant therapy. Circulation, 24,123

Baugh, C. W. (1965). An investigation of the hemorrhagic diathesis in patients receiving coumarin and indanedione anticoagulants. in patients receiving coumarin
Canad. med. Ass. J., $92,116$.

Borgström, S., Greitz, T., Linden, W. van der, Molin, J., and Rudics, I. (1965). Anticoagulant prophylaxis of venous thrombosis in patients with fractured neck of the femur. A controlled clinical trial using venous phlebography. Acta chir. scand., 129, 500.

Cleland, W. P. (1964). Anticoagulants in mitral valve surgery. Paper read at Annual Meeting of the Society of Thoracic Surgeons of Great Britain and Ireland, Birmingham.

Cooley, D. A., Beall, A. C., and Alexander, J. K. (1961). Acute massive pulmonary embolism; successful surgical treatment using cardiopulmonary bypass. J. Amer. med. Ass., 177, 283.

Cross, F. S., and Mowlem, A. (1963). Pulmonary embolectomy utilizing cardiopulmonary bypass. Surg. Gynec. Obstet., 117, 71.

Editorial (1966). The surgical treatment of acute iliofemoral thrombophlebitis. Circulation, 33, 833.

Foley, W. T., and Wright, I. S. (1956). The use of anticoagulants. An evaluation. Med. Clin. N. Amer., 40, 1339.

Jaques, L. B. (1962). Anticoagulants, thrombosis and hemorrhage. Ned. T. Geneesk., 106, 1871.
Jordan, F. L. J. (1962). De invloed van ziekten en geneesmiddelen op. patienten die met anticoagulantia worden behandeld. (Paper read at the Fourth Conference on Thrombosis Services, edited by the Dutch Red Cross.)

Kettenborg, H. K., De Vries, S. I., and van der Pol, E. T. (1955). Modifications in the behaviour of coagulation factors during storage of blood and its importance for blood transfusions. Rev. belg. Path., 24, 136.

Kluft, O., Stortenbeek, W., De Vries, S. I., and Wieberdink, J. (1965) The postoperative dip in peroperative anticoagulation. Thrombos. Diathes. haemorrh. (Stuttg.), 13, 218.

- Wieberdink, J., and De Vries, S. I. (1963). Intraveneuze toediening van coumarinederivaten. Ervaringen met warfarinenatrium. Ned. T. Geneesk., 107, 435.

Littman, J. K., and Brodman, H. R. (1955). Surgery in the presence of the therapeutic effect of dicumarol. Surg. Gynec. Obstet., 101 709 .

Lüscher, E. F. (1959). Biochemische Eigenschaften und physiologische Bedeutung der Blutplättchen. Schweiz. med. Wschr., 89, 1021.

Matis, P. (1961). Results of alternating anticoagulant prophylaxis in surgery. In Proc. Dijkzigt Conference on the Prevention of Thromboembolism in Surgery, Rotterdam, 1961 (Excerpta med. int. Congr. Ser., No. 40), p. 22.

Müllertz, S., and Storm, O. (1954). Anticoagulant therapy with Dicumarol maintained during major surgery. Circulation, 10, 213.

O'Reilly, R. A., Aggeler, P. M., and Leong, L. S. (1963). Studies on the coumarin anticoagulant drugs: the pharmacodynamics of warfarin in man. J. clin. Invest., 42, 1542 .

Sevitt, S., and Gallagher, N. G. (1961). Anticoagulant prophylaxis against venous thrombosis and pulmonary embolism in injured patients. In Proc. Dijkzigt Conference on the Prevention of Thromboembolism in Surgery, Rotterdam, 1961 (Excerpta med. int. Congr. Ser., No. 40), p. 27.

Stephenson, S. F. (1966). Anticoagulants and mitral valvotomy: a nine-year survey. Thorax, 21, 38.

Storm, O. (1958). Anticoagulant protection in surgery. Thrombos. Diathes. haemorrh. (Stuttg.), 2, 484.

- and Gammelgaard, P. A. (1957). Antithrombotic treatment in vascular surgery. Acta chir. scand., 113, 460.

- and Hansen, A. T. (1955). Mitral commissurotomy performed during anticoagulant prophylaxis with Dicumarol. Circulation, 12,981 .

Thies, H. A. (1961). Postoperative Blutgerinnungsstörungen im Zusammenhang mit Transfusionen und Infusionen. Zbl. Chir., 86, 1211 .

Tocantins, L. M. (1947). The mechanism of hemostasis. Ann. Surg.. $125,292$.

Wieberdink, J. (1960). Trendelenburg's operation for pulmonary embolism with modified technic. J. int. Coll. Surg., 34, 380. 